\title{
CHINESE COMPANIES IN SWITZERLAND
}

\author{
Kessler, E., Prandini, M., and Wu, J.
}

In recent years, some of China's leading firms have made headlines with their European expansion, by either opening new facilities or by acquiring or merging with significant enterprises in Europe. The goal of this paper is to contribute to the existing literature by examining Chinese enterprises expanding into Switzerland. The study also allows some conclusions for Chinese companies entering Central and Eastern Europe. We analyze via interviews the motivations of Chinese companies to expand into Switzerland as well as their behavior and the impediments in their internationalization process. Our findings show that Chinese companies fail to take advantage of certain benefits of western economies (such as open information and stable rule of law). To move forward efficiently, they should develop competence in dealing systematically with readily available market information, building professional networks that recognize a separation between business life and personal life, and managing their Chinese and foreign employees in the foreign cultural environment.

JEL Classification: F21, F23, M14, M16

Keywords: Globalization; foreign direct investment; Switzerland; China; Chinese enterprises

\section{Introduction}

Developed countries undertake almost two-thirds (65.4\%) of today's outward foreign direct investment ("outward FDI") (UNCTAD). Developing countries account for a minor, but growing, share of outward FDI. Of those developing countries, China's size and financial resources have positioned it to drive the changing allocation of outward FDI in the future. China has a relatively short history as a contributor to outward FDI; until 2003, outward foreign investment in China was practically non-existent. However China's outward FDI has increased more than $2000 \%$ since 2003, from 2,855 billion USD in 2003 to 84,220 billion USD in 2012 (UNCTAD). Much of this occurred during the financial crisis in 2008-09, when global outward FDI flow decreased by about $40 \%$ (UNCTAD). Chinese firms bucked that trend, seizing the opportunity to increase their outward FDI significantly. Chinese direct investment compensated for the missing investments from traditional sources, and troubled companies in Europe welcomed the influx of Chinese outward FDI. Despite this enormous increase in outward FDI, China still receives more inward FDI than its outward FDI contribution, giving it a net FDI importer status.-
In our study, we analyze Chinese FDI in Switzerland. We discuss the motives for Chinese firms to expand into Switzerland, as opposed to other destinations for Chinese outward FDI. We also investigate the difficulties Chinese firms face in Switzerland. Especially, we sought to shed light on the importance of professional networks and other soft factors for a successful integration process. To our knowledge this has not been investigated yet. Even though the study focuses on Switzerland, it also allows us to draw some conclusions regarding Chinese companies entering Central and Eastern European countries.

In our paper, we first present the theoretical background. The research questions and design follow. Then we present the empirical results and conclude with an outlook.

\section{Theoretical Background}

In the early years of China's status as a destination for inward FDI, foreign firms had to learn how to operate within the framework of Chinese politics, culture, and expectations. Now, Chinese firms must adapt in order to thrive overseas. We believe that several key differences create a commercial as well as psychological barrier to efficient operation outside of China's borders. Despite 
the development of the market system, China remains a "political economy" (Child and Tse, 2001) characterized by active governmental involvement in business through ownership and regulation. However, in negotiations with the government, it is the use of personal relationships and unofficial networks that empower Chinese firms to reach their goals. This contrasts with northern European expectations of free and accurate information, a strong rule of law, and separate networks for personal and professional relationships. Chinese firms that operate over- seas but fail to understand the expectations of the host county create unnecessary difficulties for themselves.

In the following paragraphs, we discuss the internationalization of Chinese firms using a few selected models. The Uppsala model to start with is an early, well-known internationalization model that explains the characteristics of the internationalization process as a gradual process of four stages: 1) no export; 2) export through independent representatives; 3) sales subsidiary; and, 4) production abroad (Johanson and Vahlne, 1977). According to the early Uppsala model, firms should strengthen their domestic market position and then start foreign operations with "short psychic distance" (i.e., minimal differences in language, education, culture, business practices and levels of industrial development). Firms that develop along this path will continuously increase their market knowledge and their general experience in trans-border activities, preparing for the next stage of expansion. In this model, the internationalization is a dynamic learning process (Johanson and Vahlne, 1977).

The early Uppsala model can explain some elements of the internationalization process of Chinese companies. Indeed, much of China's outward foreign direct investment takes place in Hong Kong, Southeast Asia or in other areas only a short psychic distance away. But we have also found that some Chinese companies skip some stages of the early Uppsala model by directly establishing subsidiaries in countries with larger psychic distances, including Switzerland.

Scholars have also addressed the importance of soft factors in international expansion. A number of studies demonstrated the relevance of networks in the internationalization process (Coviello and Munro, 1997; Welch and Welch, 1996). The network model by Johanson and Mattson (1988) emphases the importance of a business network for internationalization. The model discusses the importance of the firm's own business network and the relevant network in the foreign market. Having a good business network but no relevant position in the foreign market network makes it more difficult to develop business. Both a business network and a foreign market network are necessary conditions for successful internationalization. Chinese companies, being late-coming enterprises, often have no relevant position in the foreign market network. As outsiders, the lack of such market-specific business knowledge retards their internationalization.

Luo and Tung (2007) developed the emerging market springboard model. This model describes firms that systematically use international expansion as a springboard for acquiring valuable resources and assets, ultimately boosting the international positioning of emerging market companies. Through these "springboards" Chinese companies will be able to overcome their competitive disadvantages, to bypass stringent trade barriers, to overcome domestic institutional constraints and finally to become strong international competitors.

The springboard model explains several elements of the Chinese internationalization process. Through access to advanced technologies and specific industrial knowledge Chinese companies can compensate for their competitive disadvantages. Acquiring well-known foreign brands will strengthen their position in the home market and also give them the needed recognition in the international markets. Recognizing this, many Chinese companies maintain a longer-term strategic view and organize overseas operations systematically. The springboard perspective explains some elements of Chinese MNEs as well as some behavior of Chinese companies located in Western and Eastern Europe. It can be noted that Chinese companies tend to locate high-tech manufacturing and knowledge-intense services in Western Europe with M\&A as a preferred market entry strategy. Low-tech manufacturing and less knowledge-intensive services on the other hand are mostly established in Central or Eastern European countries such as Russia, Hungary or Romania. The springboard model, however, may require further development and validation to fit small and mid-sized Chinese companies that are entering the global market in a second wave of internationalization.

\section{Research Questions and Research Design}

The research questions of this study can be described as follows: Why do Chinese companies choose to locate in Switzerland? What are their difficulties? How important are their networks in this process? What are the cultural challenges? What conclusions can be drawn for other countries?

The information about Chinese companies in Switzerland was gathered primarily during guideline-based in-person 
interviews by a native Chinese citizen, although a few were done on the phone. A pre-formulated questionnaire led the interviewer, who tailored his follow-up questions to the interviewee. We believe the personal interviews were the best option for gathering useful information because Chinese people are culturally hesitant to divulge critical or negative information, requiring personal involvement by the interviewer.

In total 20 Chinese companies located in Switzerland were interviewed. The interviews were conducted with a senior member of management or with the CEO. We tried to interview both the European and Chinese managers. Documentation in the form of tape recording was rejected as many interviewees refused it. We took structured notes during the interview and a detailed report of each interview was written immediately afterwards. The questionnaire consists of 55 questions that can be divided into four different categories. Part 1 covers questions about the firm's general characteristics such as size or branch. Part 2 are questions about the process of establishing a company, whereas part 3 comprehends questions about running a business in Switzerland. Part 4 contains questions related to intercultural challenges. To our knowledge, this is the only study that investigates the establishment of Chinese companies and their integration process in Switzerland.

\section{Empirical Results}

In this section our results are presented. First, we give an overview of the interviewed companies and some important characteristics of them. Then we outline why Switzerland is a preferred location. Later we discuss differences in personal and professional networks and other cultural factors that appear to have hampered these companies.

\section{Overview of the Interviewed Companies}

Today there are 50 Chinese companies located in different cantons in Switzerland. In contrast to other countries, we do not find a concentration in one region. The interviewed companies differ in many aspects and are active in different industries. Table 1 gives an overview of the industries the 20 interviewed companies are in.

We would like to stress four important shared characteristics of the companies we interviewed. First, most of the interviewed Chinese companies have been in Switzerland for a short period of time; $50 \%$ of them were established after 2008 and only two of them (10\%) have been located in Switzerland for over 10 years. Second, the interviewed companies are small or medium-sized companies. This is consistent with the other Chinese firms operating in Switzerland; a single outlier with 500 employees is by far the largest we surveyed. Third, the vast majority of the employees of Chinese companies in Switzerland are ethnically European: $94 \%$ of their staff is European and only $6 \%$ are Chinese. Finally, the Chinese government is a significant force behind the investment process of Chinese companies.-

\section{Table 1 Overview of the industries of the interviewed companies}

\begin{tabular}{|l|c|}
\hline Industry & Number of companies \\
\hline Manufacturing & 3 \\
\hline Construction & 1 \\
\hline Aviation & 1 \\
\hline Tobacco & 1 \\
\hline Trading & 1 \\
\hline Consulting & 1 \\
\hline Banking and Finance & 1 \\
\hline Information Technology & 1 \\
\hline Watches & 4 \\
\hline Oil / Mineral & 1 \\
\hline Solar Energy & 3 \\
\hline Telecommunication & 2 \\
\hline
\end{tabular}

Source: Own survey

\section{Switzerland is not yet a Preferred Location}

The Uppsala model (Johanson and Vahlne, 1977, 2009) states that success in the domestic market is a precondition for foreign direct investment. The majority of the interviewed Chinese companies are in-line with this statement; $60 \%$ of the interviewed enterprises self-reported being number one in China and $25 \%$ even reported being number one worldwide. This indicates Chinese companies in Switzerland are well-positioned in the domestic market. Domestic success gives them the financial resources to enter new markets. Further, the Uppsala model (Johanson and Vahlne, 1977, 2009) assumes a gradual internationalization process and demonstrates that a company usually starts its business in a region with smaller psychic distance. Thirty-five percent of the interviewed companies started their international expansion in a region with small psychic distance like Hong Kong or South East Asia. Sixty percent of the companies, however, did their initial foreign direct investment in a European country, with four companies (20\%) choosing Switzerland as their first foreign station. Why have $60 \%$ of the companies deviated from the gradual expansion path described in the Uppsala model, 
instead using the so-called springboard strategies (Luo and Tung, 2007) to move directly to a more challenging place like Europe?

Before answering this question we discuss the main reasons for Chinese outward FDI. As in many other countries, the increased competition in the domestic market urges Chinese companies to look for new markets. Generally market access is one of the most acknowledged motivators of FDI. Larger market size and a higher economic growth rate lead to more incoming FDI (Kang and Jiang, 2010) and Chinese FDI to developed hosts is driven by market size and GDP (Kolstad and Wiig, 2012). The reasons for Chinese companies to invest in foreign countries are resource seeking, natural resources, geographic growth, market seeking and diversification, strategic asset seeking, global profile building and reputation (Buckley et al., 2007; Deng, 2004; Globerman and Shapiro, 2002; Kolstad and Wiig, 2012; KPMG, 2010; Seth and Yaprak, 2012). Seventy percent of the interviewed Chinese firms report that they came to Switzerland for skilled labor. Forty percent reported the "Switzerland" brand was an important factor; 35\% found the geographical location important, with another $35 \%$ reporting political stability as an important reason. Proximity to customers was important for another $30 \%$ of the firms. Another $30 \%$ of the companies report that low taxes are essential. For $70 \%$ another individual and specific factor is crucial. The reasons to locate in Switzerland are illustrated in Figure 1.

We expected to find that Swiss branding was a key motive for locating in Switzerland. The Swiss brand stands for quality and advanced technology which is highly valued in China, and many Chinese companies reported they want to use the label "Swiss Made." This is consistent with the springboard model, in which Chinese companies internationalize in order to seek assets or use internationalization as a springboard to overcome their latecomer disadvantage in the global competition (Luo and Tung, 2007). They realized that competing on low cost is not enough but an improvement in their skills, knowledge and product quality is essential. The springboard behavior often involves a series of aggressive, risk-taking behavior such as buying critical assets from mature multinational companies (Luo and Tung, 2007).

The reasons to locate a subsidiary in Switzerland are linked to the functions the subsidiary will take over in Switzerland. Figure 2 confirms that Chinese companies in Switzerland seek access to foreign markets; $85 \%$ of the subsidiaries functioned as sales offices and $65 \%$ of the subsidiaries provided customer service. This focus on

Figure 1 Reasons to locate a subsidiary in Switzerland

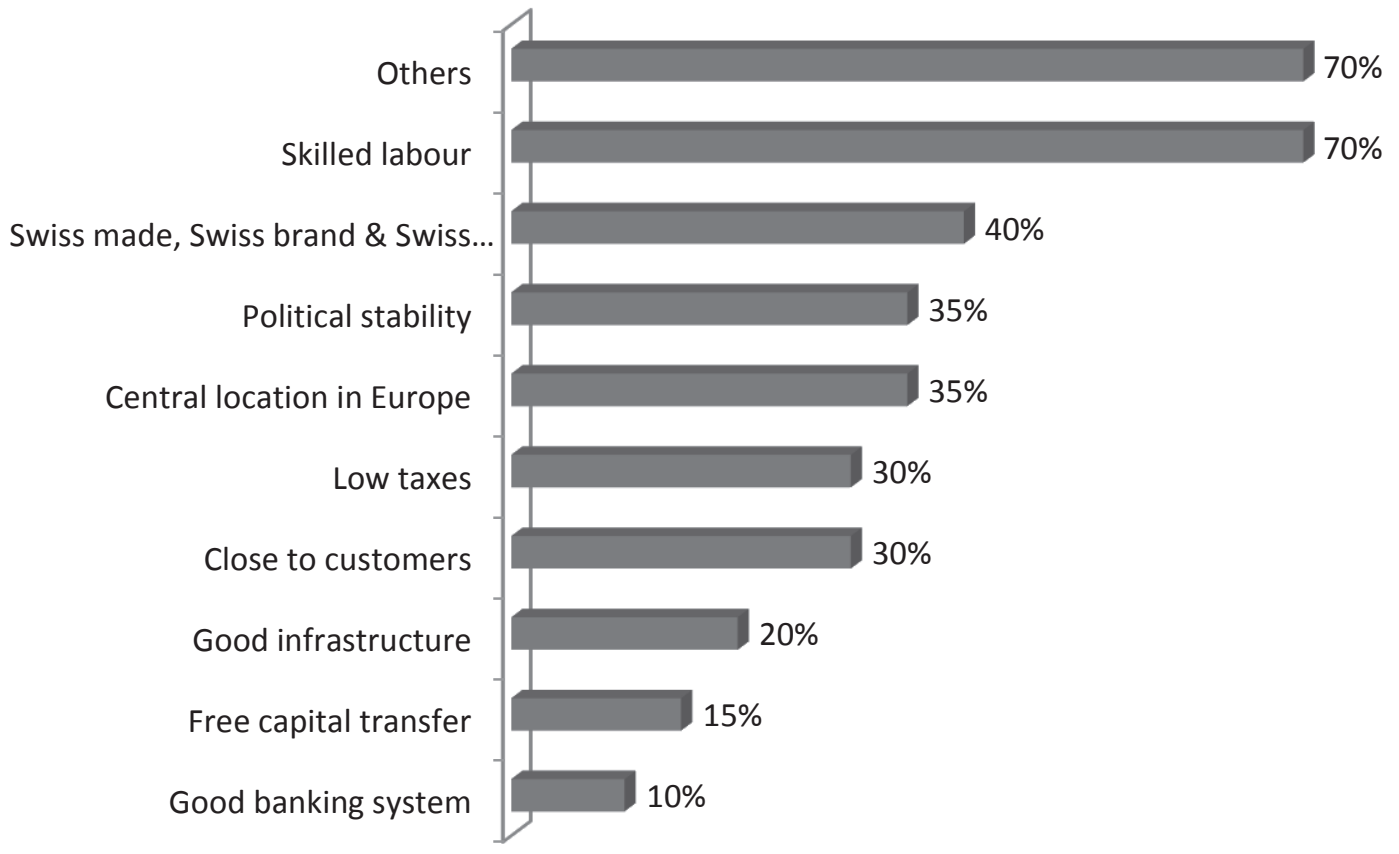

Source: Own survey 
Figure 2 Functions of the Swiss subsidiary

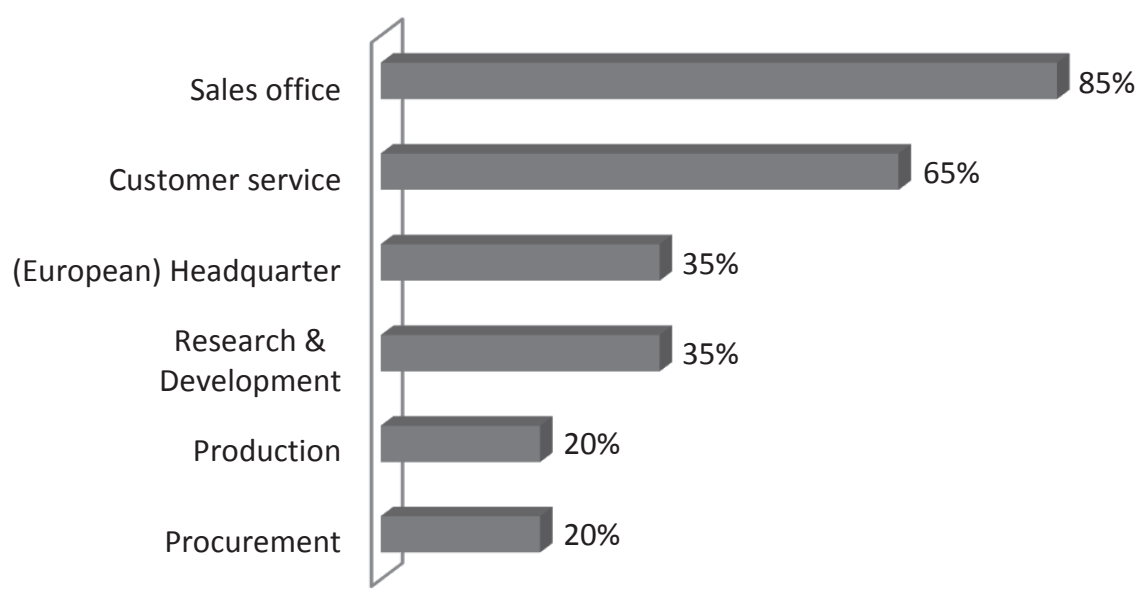

Source: Own survey

the establishment and development of their sales channel also indicates that many of the Chinese companies are in the early stages of internationalization according to the Uppsala model.

Thirty-five percent of the companies maintain research and development capabilities in Switzerland. Of the interviewed firms, only $35 \%$ also maintained a global or regional headquarters in Switzerland. For those companies, low corporate taxes were one of the main factors driving their location choice (Becker, Fuest and Riedel, 2012). The tax advantage of Switzerland in comparison to other European countries is often unknown by many Chinese entrepreneurs.

Switzerland is valued as a good place to get access to new technology and to research and development. Human capital is one of the major factors Switzerland can offer (World Economic Forum, 2011). Production and procurement play an important role for some industries but not for the majority.

Figure 2 also explains why the proportion of Chinese companies in Switzerland is small relative to other European countries such as Germany. The obvious disadvantage of Switzerland is the small domestic market. Chinese companies highly value a large domestic market - probably even overestimate it. This is not surprising as many Chinese companies grew rapidly and made money through their own large domestic market. Often the management is not fully aware that they can access the whole European market through Switzerland. For Central and Eastern European countries though, the focus of Chinese companies would be in the area of production and manufacturing. It is obvious that only $20 \%$ of the interviewed companies see Switzerland as a production location due to high labor and manufacturing costs. As many Central and Eastern European countries have similar low-cost structures like China, production is thus preferably located in Central and Eastern European countries with BYD Electronics as one example, having recently established manufacturing facilities in Hungary and Romania.

\section{Private Network versus Professional Business Network}

Cultural differences, which are often seen as a source of conflict, have received substantial attention by scholars and practitioners. Numerous empirical studies showed that cultural and organizational differences contribute to poor performance (Schoenberg, 2004; Weber and Schweiger, 1992; Weber, Shenkar and Raveh, 1996). Business culture is defined as the culture in which people do business and how they interact with each other while doing business. The concept of business culture includes norms, individual values and organizational values, working language, symbols, beliefs and working habits (Hofstede, 2001). Switzerland and China have business cultures that differ greatly. To solve difficulties Swiss managers are used to seeking professional help from individuals with whom they have no personal relationship. Chinese culture is famous for its collectivistic and network-oriented nature. To solve difficulties Chinese managers tend to seek help within their network and are not used to venturing beyond it to obtain professional help. 
Figure 3 Percentage of companies wishing additional information on different topics

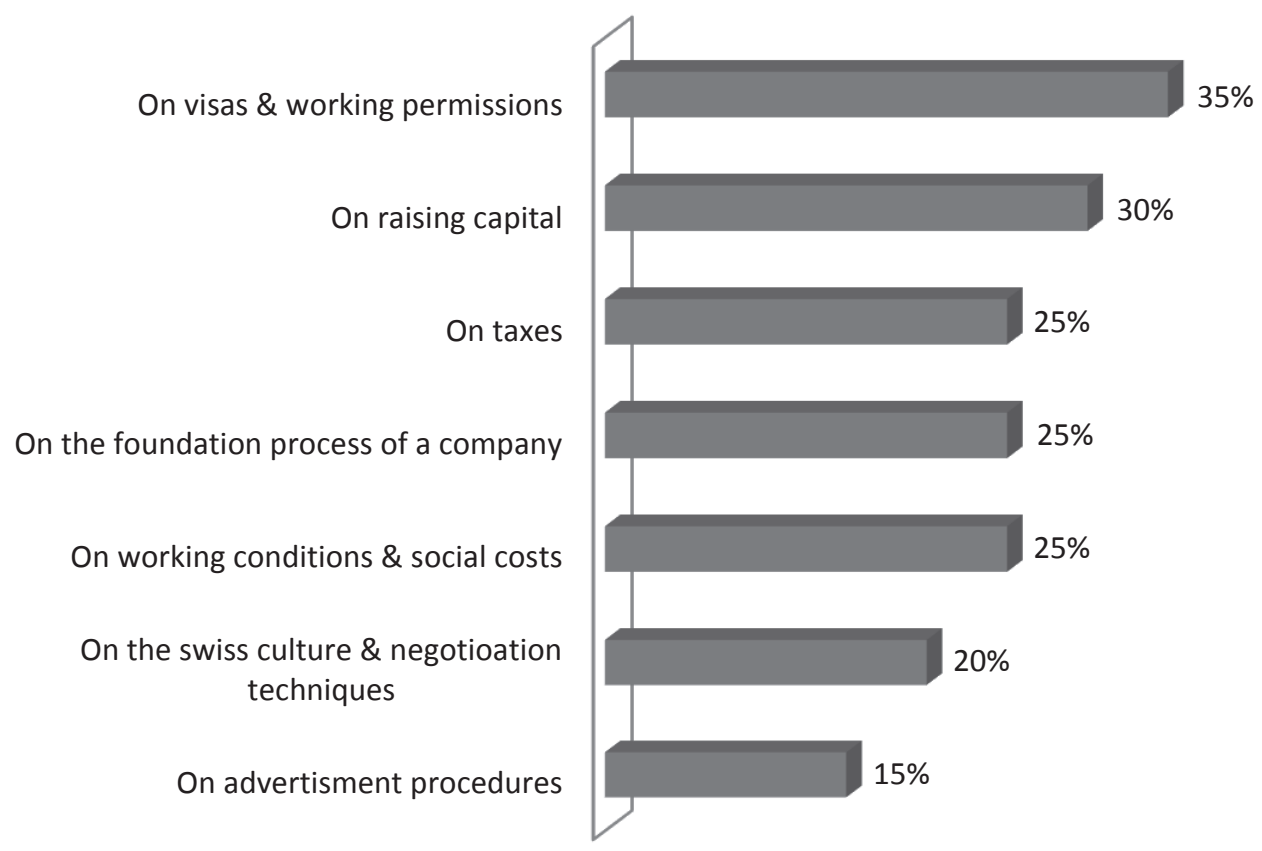

Source: Own survey

Chinese and Swiss firms and decision makers gather information differently. About $50 \%$ of the Chinese firms relied on internal information, via information from partner companies and friends. Thirty-five percent of the firms trusted information of the Chinese embassy in Bern and the Commercial and Trade Consulate. The local governments and the departments of economic promotion were contacted by $35 \%$ of the firms. Professional business consultants were only involved in $30 \%$ of the cases. Although the Internet contains ample relevant information about investment conditions, only a minority of Chinese firms (15\%) used websites like www.swissinfo.ch or www.s-ge.com (former osec.ch), even though they are available in Chinese. Only 5\% of the firms know about the Swiss promotional agency Switzerland Global Enterprise (former OSEC). This result reflects the fact that Chinese people tend to rely on information from friends and family in business issues more than Western firms do.

The differences in information gathering techniques do appear to put Chinese firms at a disadvantage. Figure 3 lists the percentage of interviewed companies that wanted additional information on selected topics. Forty percent of the Chinese companies are not aware of the amount of social security contributions that have to be paid in Switzerland.
This result is surprising to us because much of this information can be easily found on the Internet for free in English, including the regulations for visas and working permission, tax system, working regulations, social security cost, and the process for creating a business entity. This may be explained once again with the way Chinese people gather information (so-called Guanxi) and their dependence on private networks. A few interviewed managers said that the official information in China is only propaganda and has no real meaning. Chinese people are less willing to pay for professional information and consulting. A business network that is effective and efficient includes relationships to all business counterparties including clients, delivery companies, distributors, competitors, lawyers, and local government and so on.

\section{Cultural Differences and the Image of China}

Collaboration between employees is essential for any company. In the following question only companies that have both Chinese and European employees are analyzed (16 companies). Thirteen percent of the interviewed firms report a harmonious collaboration and $31 \%$ a neutral collaboration between Chinese and Swiss employees. In those firms, the employees are often well-educated and the corporate language is 
English. But $56 \%$ of the interviewed companies said that the collaboration between Chinese and Swiss employees is difficult, making internal collaboration an ongoing struggle. The Chinese view of teamwork is hierarchical and stresses following instructions by line management, in contrast to the more egalitarian and collegial model used in Western organizations. In addition, Chinese employees are dissatisfied with the fact that many European employees separate professional and private life. For $25 \%$ this is not relevant as they have no Chinese employees.

Social conflicts have the potential to disturb knowledge transfer and to lead to a failure of the acquisition process (Vaara et al., 2012). Cultural differences and the resulting social conflicts have to be taken seriously. One might think that the main problem behind this is language barriers; this is not the case. Language barriers were only in 19\% of the cases a real problem as English is often the corporate language. Eighty-one percent of the Chinese companies in Switzerland see psychological and cultural differences as the main cause of the failure in cooperation. Different cultures lead to different working and management styles, resulting in conflicts throughout every level of the organization. Forty-five percent of the interviewed companies report that they often suffer due to the bad image of China. Another 35\% do so sometimes and 5\% suffer seldom. Only $10 \%$ of the interviewed firms reported never suffering. Factors leading to the negative image of Chinese companies include reports about violations of human rights, piracy and violations of intellectual property laws, and early outward FDI from China to Africa or Asia (Kolstad and Wiig, 2012).

It is clear that from the moment a firm enters a host country, they must meet corporate and social expectations and demonstrate corporate social responsibility. This will allow them to build social legitimacy in the host country. The larger the cultural distance between the country of origin and host country, the more difficult it will be to attain this social legitimacy. It is exactly this social legitimacy that Chinese companies in Switzerland seek but also are struggling with. Regarding cultural differences, the gap is supposed to be smaller between Chinese and Central and Eastern European companies due to a common history and a cultural heritage with high power distance as well as high family and group collectivism. Those similar cultural practices and orientations are in favor of Central and Eastern European countries when welcoming Chinese companies in their domestic market.

\section{Conclusion and Managerial Implications}

In conclusion, Chinese companies have little experience in leading enterprises abroad and therefore make beginners' mistakes. They are often disadvantaged when entering into foreign markets, and only a few Chinese brands have achieved worldwide recognition. Most of the Chinese companies in Switzerland are doing business in a Chinese way. Instead of establishing an extensive business network they continue to rely mainly on their private network. Rather than making use of professional services such as consulting, they prefer to learn by trial and error. This behavior often leads to suboptimal decisions and increases the cost of the internationalization process. Cooperation between employees is essential for the integration process and business development. The existing intercultural difficulties need to be addressed and overcome. Intercultural training would help to reduce this problem. The main motivations to settle down in Switzerland are brand building, access to the label "Switzerland" and strategic assets. Some other significant advantages of Switzerland, such as an efficient tax system and a good banking system, are unknown and underestimated among Chinese companies. This is attributable to their lack of international experience and lower degree of internationalization. The recently signed free trade agreement between China and Switzerland opens new perspectives for both sides. We anticipate that more Chinese companies will invest in Switzerland and the two countries will be linked more closely. With the increasing interaction of both countries their mutual understanding will be improved.

It can be assumed that Chinese companies apply similar motivations, practices and behaviors when internationalizing towards Central and Eastern Europe. When looking at Europe, Chinese companies tend to see the European market as an entity, not being aware of economic, political and cultural differences. Due to given experiences, Central and Eastern European countries are preferably chosen as manufacturing locations. Hereby the comparative cost advantage is a main motivational driver for Chinese companies to locate, but still needs to be promoted more intensively. Similarly as in Switzerland, the official economic promotion agencies can increase their impact on attracting Chinese OFDI. Business practices and behaviors of Chinese managers can be assumed to be the same when expanding towards Central and Eastern Europe. As mentioned above, the cultural differences might be on a smaller scale, but will also need to be reconciled for successful and long-term business relationships.

Until now most research related to Chinese companies' targets top listed MNE. In this study, we focused on Chinese SMEs in Switzerland. Further research will investigate the general internationalization level of 
Chinese companies and their decision making process. A research focus hereby should be given on the internationalization strategies and processes of Chinese SMEs originating from the private sector.

\section{References}

Becker, J., Fuest, C., Riedel, N. (2012). Corporatee tax effects on the quality and quantity of FDI. European Economic Review, 56 (8): 1495-1511.

Buckley, P. J., Clegg, L. J., Cross, A. R., Liu, X., Voss, H., Zheng, P. (2007). The determinants of Chinese outward foreign direct investment. Journal of international business studies, 38 (4): 499-518.

Child, J., Tse, D. K., (2001). Chinas transition and its implications for international business. Journal of international business studies, 32 (1): 5-21.

Coviello, N., Munro, H. (1997). Network relationships and the internationalisation process of small software firms. International business review, 6 (4): 361-386.

Deng, P. (2004). Outward investment by Chinese MNCs: Motivations and implications. Business Horizons, 47 (3): 8-16.

Globerman, S., Shapiro, D. (2002). Global foreign direct investment flows: the role of governance infrastructure. World Development, 30 (11): 1899-1919.

Hofstede, G. (2001). Culture's consequences: Comparing values, behaviors, institutions and organizations across nations. Sage Publications, Incorporated.

Johanson, J., Mattsson, L.-G. (1988). Internationalization in industrial systems- a network approach. Strategies, 1988, 287-314.

Johanson, J., Vahlne, J.-E. (1977). The internationalization process of the firm-a model of knowledge development and increasing foreign market commitments. Journal of international business studies, 1977, 23-32.

Johanson, J., Vahlne, J.-E. (2009). The Uppsala internationalization process model revisited: From liability of foreignness to liability of outsidership. Journal of international business studies, 40 (9): 1411-1431.

Kang, Y., Jiang, F. (2010). FDI location choice of Chinese multinationals in East and Southeast Asia: Traditional economic factors and institutional perspective. Journal of World Business, 47 (1): 45-53.

Kolstad, I., Wiig, A. (2012). What determines Chinese outward FDI? Journal of World Business, 47 (1): 26-34.

KPMG. (2010). World class aspirations: The perceptions and the reality of China outbound investment. KPMG China.

Luo, Y., Tung, R. L. (2007). International expansion of emerging market enterprises: A springboard perspective. Journal of international business studies, 38(4): 481-498.
Schoenberg, R. (2004). Dimensions of management style compatibility and cross-border acquisition outcome. Advances in Mergers and Acquisitions, 3, 149-175.

Seth, T., Yaprak, A. (2012). Outward Foreign Direct Investment by Chinese Firms: Institutional Theory and Resource Dependence Perspectives. Impacts of Emerging Economies and Firms on International Business, 32.

Vaara, E., Sarala, R., Stahl, G. K., Björkman, I. (2012). The impact of organizational and national cultural differences on social conflict and knowledge transfer in international acquisitions. Journal of Management Studies, 49 (1): 1-27.

Weber, Y., Schweiger, D. M. (1992). Top management culture conflict in mergers and acquisitions: A lesson from anthropology. International Journal of Conflict Management, 3 (4): 285-302.

Weber, Y., Shenkar, O., Raveh, A. (1996). National and corporate cultural fit in mergers/acquisitions: An exploratory study. Management science, 42(8): 1215-1227.

Welch, D. E., Welch, L. S. (1996). The internationalization process and networks: a strategic management perspective. Journal of international marketing, 11-28.

World Economic Forum. (2011). The Global Competitiveness Report 2011 - 2012. Geneva.

Authors

Esther Kessler, Ph.D. Lecturer and Researcher for Economics and International Business

Regional Competence Center Asia-Pacific Zurich University of Applied Sciences (ZHAW) School of Management and Law Stadthausstrasse 14, CH-8401 Winterthur esther.kessler@zhaw.ch

Markus Prandini, Ph.D. HSG

Professor for International Business Head of Competence Center Asia-Pacific Zurich University of Applied Sciences (ZHAW)

School of Management and Law Stadthausstrasse 14, CH-8401 Winterthur markus.prandini@zhaw.ch

Juan Wu, MSc.

Researcher for International Business with a focus on China

Regional Competence Center Asia-Pacific Zurich University of Applied Sciences (ZHAW) School of Management and Law Stadthausstrasse 14, $\mathrm{CH}-8401$ Winterthur juan.wu@zhaw.ch 